\title{
Two Sites of Bile Formation as Determined by Mannitol and Erythritol Clearance in the Guinea Pig*
}

\author{
E. L. FORKER $\dagger$ \\ (From the Department of Physiology and Biophysics and the Gastroenterology Research \\ Laboratories, Department of Medicine, The University of Iowa, \\ Iowa City, Iowa)
}

\begin{abstract}
Summary. If water and inert solutes are assumed to pass from blood to bile through a fixed population of membrane pores, the changes in clearance pro-duced by dehydrocholate suggest that osmotic filtration rather than diffusion is the predominant mode of transfer for mannitol and erythritol. Bile produced in the canaliculi is modified in the interlobular ducts by the action of secretin. If distal fluid transfer is an important determinant of the choleresis evoked by dehydrocholate, the mechanism appears to effect a net secretion or reabsorption of fluid at a rate roughly proportional to the rate of flow in the canaliculi.
\end{abstract}

\section{Introduction}

The biliary excretion of lipid insoluble, metabolically inert solutes, though recognized for some time, has received relatively little attention (1-3). Parenchymal liver cells are uniquely permeable to a number of inert carbohydrates, and it has been assumed on this basis that their entrance into bile is by way of the intralobular bile capillaries (canaliculi) (2). No study appears to have been made, however, of the effect of choleretics on this process.

Bile salts are thought to exert their primary choleretic effect in the canaliculi (4). Recently additional evidence has been presented suggesting that the interlobular ducts may also be an important site of fluid transfer $(5,6)$. On the assumption that excretion of mannitol and a somewhat smaller solute, erythritol, might be enhanced by increases in canalicular flow but not by fluid transfer at less permeable distal loci, experiments

* Submitted for publication December 5, 1966; accepted March 23, 1967.

Supported by U. S. Public Health Service grant AM09892.

Abstracted in J. Lab. clin. Med. 1966, 68, 875.

$\dagger$ Markle Scholar in Academic Medicine; Research Associate, Veterans Administration Hospital, Iowa City, Iowa.

Address requests for reprints to Dr. E. L. Forker, Dept. of Physiology and Biophysics, University of Iowa, Iowa City, Iowa 52240 . have been designed to study the relationship of biliary clearance to the rate of bile flow and the molecular size of the test solute. The results clarify some of the features of canalicular bile formation during dehydrocholate choleresis and support an earlier postulate (5) that secretin exerts its choleretic effect in the intralobular ducts.

\section{Methods}

Guinea pigs ( 250 to $300 \mathrm{~g}$ body wt) were anesthetized with ip allobarbital (60 $\mathrm{mg}$ per $\mathrm{kg}$ ) and urethane (240 $\mathrm{mg}$ per $\mathrm{kg}$ ). The trachea was connected to a respirator, and functional nephrectomy and cholecystectomy were achieved by ligating the renal pedicles and the cystic duct. Bile was collected from a small polyethylene catheter in the common duct. Fluid losses were replaced continuously with an iv infusion of $2.5 \%$ glucose, $0.4 \% \mathrm{NaCl}$. Body temperature $\left(38^{\circ} \mathrm{C}\right)$ and weight were constant throughout the experiments. Under these circumstances bile flow was stable for 4 hours or longer.

After an initial sample of bile had been obtained for determination of background counting rate, each animal received a single iv injection of $3 \mu \mathrm{c}$ of erythritol ${ }^{14} \mathrm{C}^{1}$ and $15 \mu \mathrm{c}$ of mannitol- ${ }^{8} \mathrm{H} .{ }^{2}$ Some animals received additional unlabeled mannitol or erythritol calculated to produce a final plasma concentration of 5 mmoles per $\mathrm{L}$, approximately 700 times greater than the plasma level achieved when the radioactive solutes were given alone. The timing of subsequent procedures was as follows. Plasma radioactivity was allowed to stabilize from in-

1 Nuclear Chicago Corp., Des Plaines, Ill.

2 New England Nuclear Corp., Boston, Mass. 
jection of the test solutes $(t=0)$ to $t=110$ minutes. The first clearance period lasted from $t=110$ to $t=120$. The radioactivity in bile collected over this interval was compared with the radioactivity in plasma obtained from $75 \mu$ l of carotid arterial blood removed at the midpoint $(t=115)$. At $t=120$ an iv infusion of sodium dehydrocholate in distilled water $(100 \mathrm{mg}$ per $\mathrm{ml})$ or Boots secretin in $0.9 \% \mathrm{NaCl}$ solution ( $7.5 \mathrm{U}$ per $\mathrm{ml}$ ) was begun and continued for the rest of the experiment. The choleretic injections were given manually by syringe. Total doses were approximately $100 \mathrm{mg}$ of dehydrocholate or $5 \mathrm{U}$ of secretin. Maximal choleresis was achieved within 5 minutes by giving a quarter of the dose abruptly. Constant bile flow was maintained by giving the remainder of the choleretic slowly during the ensuing 30 minutes. Twenty minutes $(t=125$ to $t=145$ ) was allowed for attaining a steady state at the new higher rate of bile flow. Previous experiments (6) have shown that 20 minutes exceeds 10 mean transit times (approximately 5 dead space volumes) for the biliary tree and the collecting cannula. From $t=$ 145 to the end of the experiment at $t=150$ a second bile sample was collected for determination of clearance during choleresis. Average bile flow rate during the clearance periods was determined by weighing the collected bile. In addition, a recording dropcounter provided a continuous record of bile flow to ensure that flow rate was stable before and during the clearance periods. At the end of the experiment animals were killed by exsanguination. Blood collected at this time was used to estimate clearance rates during the preceding 5 minutes.

Half of each liver (about $5 \mathrm{~g}$ ) and approximately $2 \mathrm{~g}$ of muscle from the abdominal wall were homogenized with equal volumes of $10 \%$ trichloroacetic acid in a high speed Sorvall microhomogenizer. Bile, plasma, and the supernatant from tissue homogenates were put in Bray's solution (7), and the radioactivity was measured in a 3-channel liquid scintillation spectrometer. Sample volumes $(50 \mu 1$ of bile and tissue homogenate, $20 \mu 1$ of plasma) were minimized to reduce quenching. Separation of ${ }^{14} \mathrm{C}$ from ${ }^{3} \mathrm{H}$ was better than $90 \%$. Small corrections required for incomplete discrimination and for variations in counting efficiency were determined by internal standardization. Total error in the preparation and counting of radioactive samples was approximately $7 \%$. Tissue water was determined by drying to constant weight at $80^{\circ} \mathrm{C}$. The heptane and olive oil to water partition ratios of mannitol and erythritol were less than 0.0003 .

Bicarbonate concentration was determined in bile collected anaerobically under mineral oil. Total $\mathrm{CO}_{2}$ was measured volumetrically in a microgasometer, and $\mathrm{pH}$ was determined with a capillary electrode. Bicarbonate concentration was estimated from the Henderson-Hasselbalch equation.

Bile was subjected to descending chromatography on Whatman 3 filter paper in 3 solvent systems : 1-butanol : acetic acid : $\mathrm{H}_{2} \mathrm{O}$ (4:1:5), 1-butanol: ethanol: $\mathrm{H}_{2} \mathrm{O}$ (4: $1: 5)$, and ethyl acetate: pyridine: boric acid (12:5:4). The radiochromatograms were scanned with a windowless gas flow counter.
Results are expressed as the mean and standard deviation, or where specified the $95 \%$ confidence interval is given as computed from conventional estimates of variance and Student's distribution (8).

\section{Results}

Biliary clearance, $\mathrm{C}$, was determined from the equation,

$$
\mathrm{C}=\mathrm{F}[x]_{\mathrm{b}} /[x]_{\mathrm{p}},
$$

in which the terms in brackets designate the concentration of the test solute, $x$, in bile and plasma water and $\mathrm{F}$ is the rate of bile flow in microliters per minute per gram liver weight. The results obtained with dehydrocholate appear in Figure 1. The clearance slopes $(\Delta \mathrm{C} / \Delta \mathrm{F})$ and their ratios, which display less variation, are given in Table I. The results obtained with secretin appear in Figure 2. The mean increment in bile flow following secretin $\left(3.1 \mu \mathrm{l}\right.$ minute $\left.^{-1} \mathrm{~g}^{-1}\right)$ was only half as great as that seen with dehydrocholate

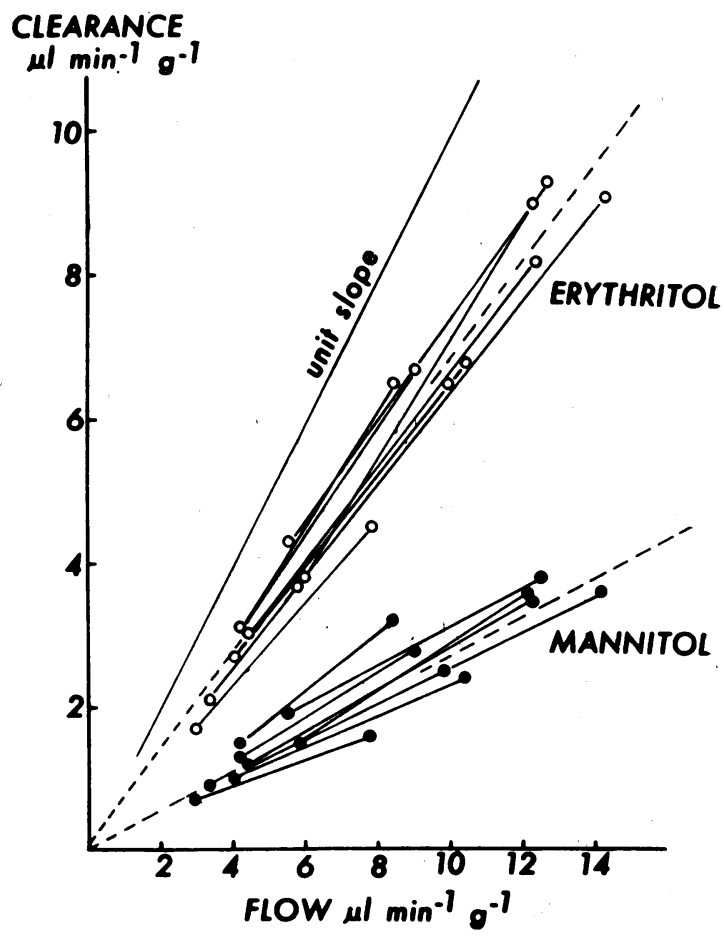

Fig. 1. The change in Clearance during dehydroCHOLATE CHOLERESIS. Broken lines indicate mean results. Erythritol: $C=0.68( \pm 0.06) \mathrm{F}+0.11( \pm 0.37)$. Mannitol: $\mathrm{C}=0.27( \pm 0.05) \mathrm{F}+0.02( \pm 0.19) . \quad \pm=95 \%$ confidence interval. $\mathrm{C}=$ biliary clearance; $\mathrm{F}=$ rate of bile flow. 
TABLE I

Change in clearance of inert solutes during dehydrocholate choleresis

\begin{tabular}{|c|c|c|c|c|c|}
\hline \multirow{2}{*}{$\begin{array}{c}\text { Liver } \\
\text { weight }\end{array}$} & \multicolumn{2}{|c|}{ Bile flow } & \multicolumn{2}{|c|}{$\begin{array}{l}\text { Clearance slope } \\
=\Delta \mathrm{C} / \Delta \mathrm{F}^{*}\end{array}$} & \multirow{2}{*}{$\begin{array}{l}\text { Slope } \\
\text { ratio }\end{array}$} \\
\hline & Initial & Final & Erythritol & Mannitol & \\
\hline$g$ & \multicolumn{2}{|c|}{$\mu l \min ^{-1} g^{-1}$} & & & \\
\hline 11.03 & 5.9 & 14.2 & 0.64 & 0.26 & 2.5 \\
\hline 14.07 & 4.2 & 10.0 & 0.63 & 0.26 & 2.4 \\
\hline 9.61 & 5.8 & 12.2 & 0.81 & 0.33 & 2.5 \\
\hline 8.31 & 4.2 & 8.4 & 0.82 & 0.42 & 2.0 \\
\hline 8.25 & 5.4 & 12.6 & 0.69 & 0.27 & 2.6 \\
\hline 8.25 & 4.0 & 10.4 & 0.67 & 0.22 & 3.0 \\
\hline 9.32 & 3.3 & 9.9 & 0.66 & 0.23 & 2.9 \\
\hline 9.90 & 4.4 & 12.2 & 0.67 & 0.28 & 2.2 \\
\hline 9.63 & 2.9 & 7.8 & 0.56 & 0.20 & 2.8 \\
\hline
\end{tabular}

$* \mathrm{C}=$ biliary clearance $\mathrm{F}=$ rate of bile flow.

(6.4 $\mu \mathrm{l}$ minute $\mathrm{e}^{-1} \mathrm{~g}^{-1}$ ). Plasma radioactivity declined slowly between the midpoint of the first clearance period $(t=115)$ and the end of the experiment 35 minutes later. The average decline in plasma level expressed as a percentage of the initial value was $7 \pm 6 \%$ for erythritol and $5 \pm$ $4 \%$ for mannitol.

The relationship between solute clearance and spontaneous bile flow is shown in Figure 3. Each point represents the initial clearance in a different animal. A 700-fold increase in the plasma level of mannitol or erythritol did not result in reduced clearance as might have been expected if excretion of either solute were mediated by a carrier system of limited capacity.

The plasma equivalent tissue spaces of mannitol

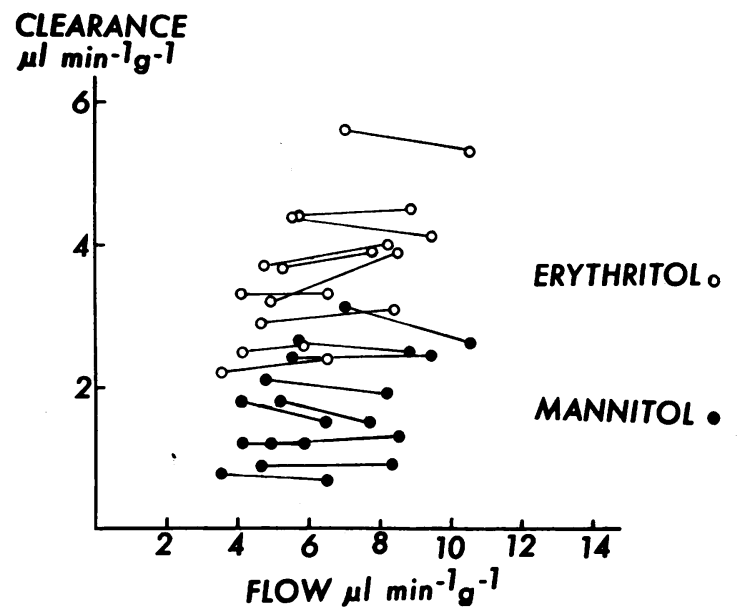

Fig. 2. The Change in CLEarance DURING SECRETIN CHOLERESIS. Erythritol: $\triangle \mathrm{C} / \triangle \mathrm{F}=0.06$ ( \pm 0.08 ). Mannitol: $\triangle \mathrm{C} / \triangle \mathrm{F}=-0.07$ ( \pm 0.09$) . \quad \pm=95 \%$ confidence interval.

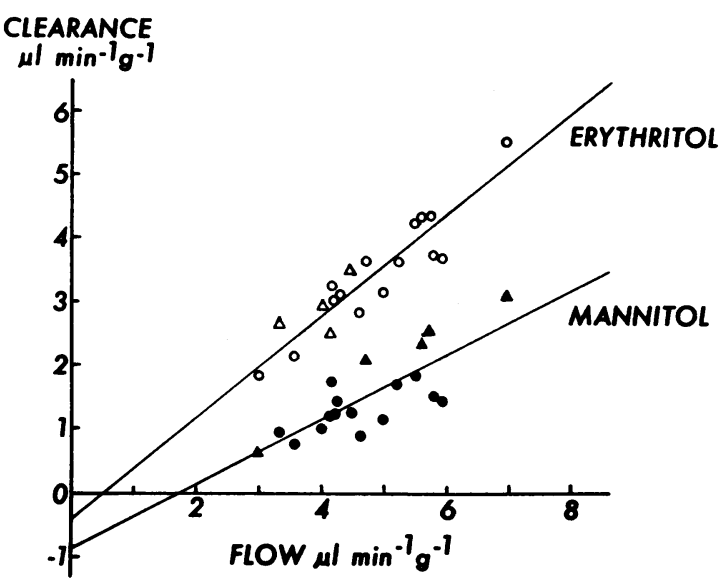

Fig. 3. Clearance as a function of spontaneous FLow. Animals receiving additional unlabeled solute are indicated by $\Delta$ (erythritol) or $\boldsymbol{\Delta}$ (mannitol). Least square regression equations: erythritol, $C=0.81( \pm 0.16)$ $\mathrm{F}-0.38( \pm 0.84)$; mannitol, $\mathrm{C}=0.51( \pm 0.19) \mathrm{F}-0.86$ $( \pm 0.94) . \pm=95 \%$ confidence interval.

and erythritol were computed as the ratio of isotope concentration in tissue water to the concentration in plasma water. Mean values for liver and abdominal muscle appear in Table II. Whereas mannitol has limited access to muscle, it invades hepatic water almost completely. The smaller molecular size of erythritol is reflected by its close approach to equilibrium in both tissues.

Both mannitol and erythritol are reported to resist oxidation by liver polyol dehydrogenase (9). To verify that erythritol and mannitol were in fact the radioactive compounds appearing in bile, samples of bile collected at the end of an experiment were compared chromatographically with previously collected bile to which the labeled compounds had been added directly. The radiochromatograms appear in Figure 4. In each case, the compound excreted in bile appeared identical with that given intravenously. No radioactivity remained at the origin or appeared at the solvent front.

Eight samples of spontaneously flowing bile contained $57 \pm 4 \mathrm{mEq}$ per $\mathrm{L}$ of bicarbonate. In four

TABLE II

Plasma equivalent tissue spaces

\begin{tabular}{lccc}
\hline & \multicolumn{2}{c}{ Fraction of tissue $\mathrm{H}_{2} \mathrm{O}$ invaded } \\
\cline { 2 - 4 } Solute & $\begin{array}{c}\text { Liver } \\
\mathrm{n}=19\end{array}$ & $\begin{array}{c}\text { Muscle } \\
\text { n }=10\end{array}$ & $\begin{array}{c}\text { Mol } \\
\text { wt }\end{array}$ \\
\hline Erythritol & $1.06 \pm 0.07$ & $0.94 \pm 0.08$ & 122 \\
Mannitol & $0.94 \pm 0.04$ & $0.35 \pm 0.06$ & 182 \\
\hline
\end{tabular}



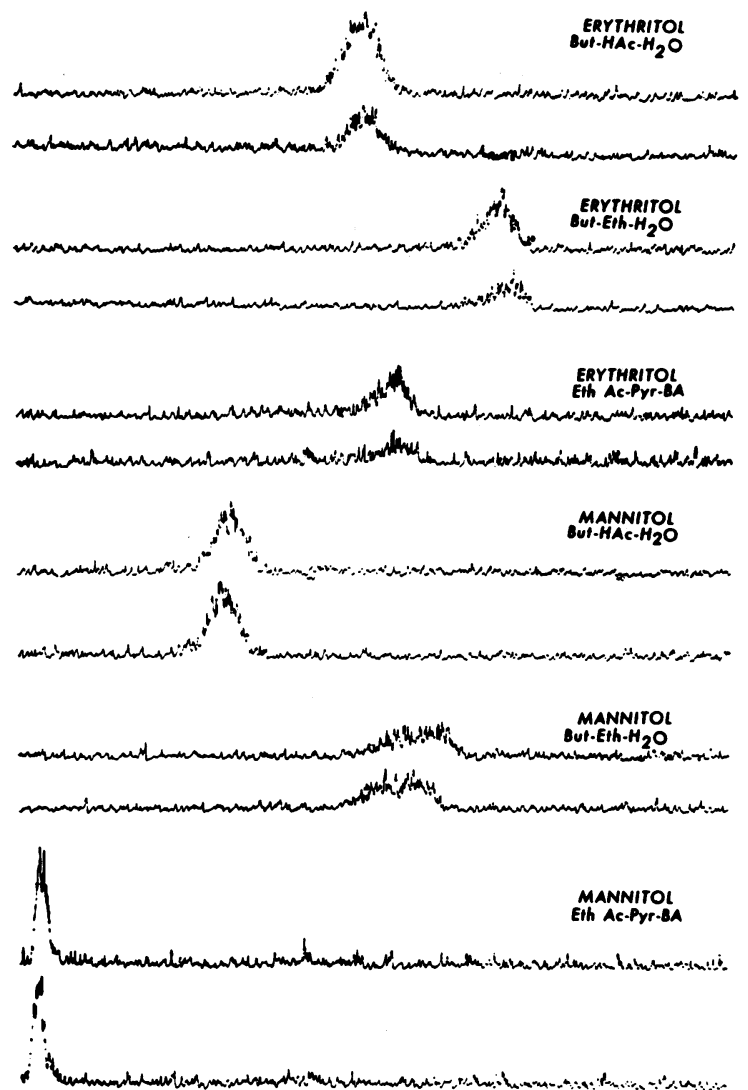

Fig. 4. Radiochromatograms. In each pair the chromatogram of the test solute appears above the chromatogram of material excreted in bile. But $=$ butanol; HAc $=$ acetic acid; eth $=$ ethanol ; eth ac $=$ ethyl acetate; $p y r=$ pyridine; $\mathrm{BA}=$ boric acid.

of these animals given dehydrocholate, bicarbonate concentration fell to $40 \pm 9 \mathrm{mEq}$ per $\mathrm{L}$. In the remaining four given secretin, the mean bicarbonate level increased to $76 \pm 5 \mathrm{mEq}$ per $\mathrm{L}$.

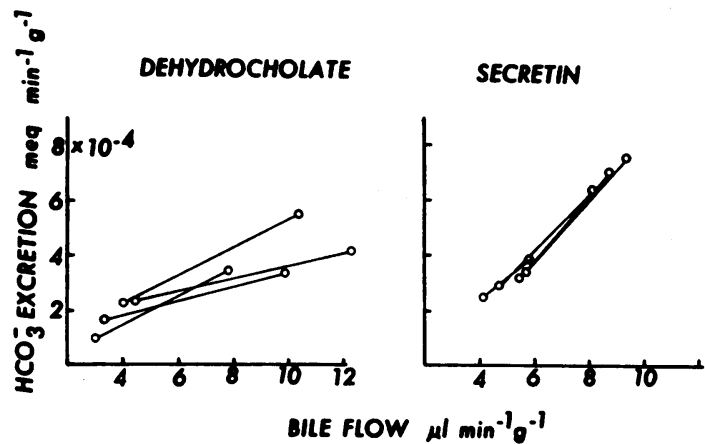

Fig. 5. The change in BICARbonate exCRetion DURING DEH YDROCHOLATE AND SECRETIN CHOLERESIS. Average slopes: dehydrocholate, $34.6( \pm 11.4) \mathrm{mEq}$ per L; secretin, $74.8( \pm 13.7) \mathrm{mEq}$ per $\mathrm{L}$.
In Figure 5 these results appear as a plot of bicarbonate excretion rate versus bile flow. The slopes of the lines represent the concentration of bicarbonate in the extra fluid recruited by the choleretic.

\section{Discussion}

The assumption that mannitol and erythritol enter canalicular bile derives from the finding that parenchymal liver cells are unusually permeable to these solutes and the postulate that dehydrocholate, which enhances their excretion, produces an osmotic choleresis at the same locus. Since the effect of secretin on solute clearance is clearly different from the effect of dehydrocholate, either secretin must exert its choleretic effect at a less permeable locus in the biliary tree, or, if it acts at the same site as dehydrocholate, it must modify the relative permeabilities of the canalicular membrane to solutes and water. Though the present data do not rigorously exclude this latter possibility, the more reasonable interpretation is that secretin promotes distal fluid secretion or inhibits distal fluid reabsorption. The electrolyte composition of bile suggests that distal alterations in fluid transfer are associated with increased bicarbonate production or suppression of its reabsorption. The existence of a ductular mechanism for modifying canalicular bile is consistent with Wheeler's interpretation of Bromsulphalein washout volumes in the dog (5) and with an analysis in this laboratory of Diodrast (iodopyracet) excretion patterns in the guinea pig (6). Both of these studies are difficult to interpret, however, because of the uncertain cellular disposition of actively secreted indicators and the fact that biliary capacity may change with flow. The present analysis proceeds from different assumptions.

Two processes are postulated to account for the clearance patterns obtained with dehydrocholate: proximal bile formation at a rate related to solute clearance and subsequent modification of this primary secretion by distal addition or subtraction of nonradioactive fluid. A theoretical relation between canalicular bile flow and the rate of solute clearance will be developed along lines suggested by Renkin (10). The model is a general one relating the passive transfer of inert solutes to the area and length of equivalent cylindrical pores Its application to the present problem depends 
upon the implicit assumptions that permeability of the canalicular membrane does not change with bile flow and that water travels the same transmembrane pathway as the test solutes. ${ }^{3}$

The contribution of diffusion to the total rate of solute excretion is given by an approximation of the Fick equation,

$$
Q_{\mathrm{d}}=\mathrm{D}_{x}\left(\mathrm{~A}_{x} / \mathrm{L}\right)\left([x]_{\mathrm{p}}-[x]_{\mathrm{b}}{ }^{\prime}\right),
$$

in which $\mathrm{D}_{x}$ and $\mathrm{A}_{x}$ are, respectively, the unrestricted diffusion coefficient and the effective pore area for a permeating solute $x$. $\mathrm{L}$ denotes the distance for diffusion (effective pore length). The concentration gradient is assumed to be uniform and is given by the difference between plasma, $[x]_{\mathrm{p}}$, and canalicular bile, $[x]_{\mathrm{b}}{ }^{\prime}$.

The rate of solute transfer effected by solvent flow is related to the product of canalicular flow, $f$, and plasma concentration by the ratio of effective pore areas for solute and water. Thus, solute excretion attributable to filtration is

$$
Q_{\mathrm{s}}=[x]_{\mathrm{p}} \mathrm{f}\left(\mathrm{A}_{x} / \mathrm{A}_{\mathrm{w}}\right) \text {. }
$$

Adding the rates for diffusion and filtration gives $Q$, the total rate of transfer from plasma to bile, which is also the product of flow and bile concentration, so that

$$
Q_{\mathrm{d}}+Q_{\mathrm{s}}=Q=[x]_{\mathrm{b}}{ }^{\prime} \mathrm{f} .
$$

Substitution from Equations 2 and 3 yields an expression for plasma clearance in terms of canalicular bile flow, the free diffusion coefficient for solute, and equivalent pore dimensions.

$$
\mathrm{C}=\mathrm{Q} /[x]_{\mathrm{p}}=\frac{\mathrm{f}^{2}+\mathrm{D}_{x}\left(\mathrm{~A}_{\mathrm{w}} / \mathrm{L}\right) \mathrm{f}}{\left(\mathrm{A}_{\mathrm{w}} / \mathrm{A}_{x}\right) \mathrm{f}+\mathrm{D}_{x}\left(\mathrm{~A}_{\mathrm{w}} / \mathrm{L}\right)} .
$$

The form of Equation 5 is shown in Figure 6. At low rates of flow, clearance approaches the rate of bile formation, reflecting the approach to diffusion equilibrium between canalicular bile and plasma. As flow increases, the contribution made by diffusion approaches a limiting value, and beyond this point increments in clearance are wholly the result of increased filtration. The magnitude of the filtration effect is measured by the slope of

${ }^{3}$ For simplicity the derivation is given for a population of uniform pores, but this is not an essential restriction. Equation 5 may be derived for each class of pores and the individual transfer rates summed provided that each pore class contributes a constant fraction of canalicular flow.

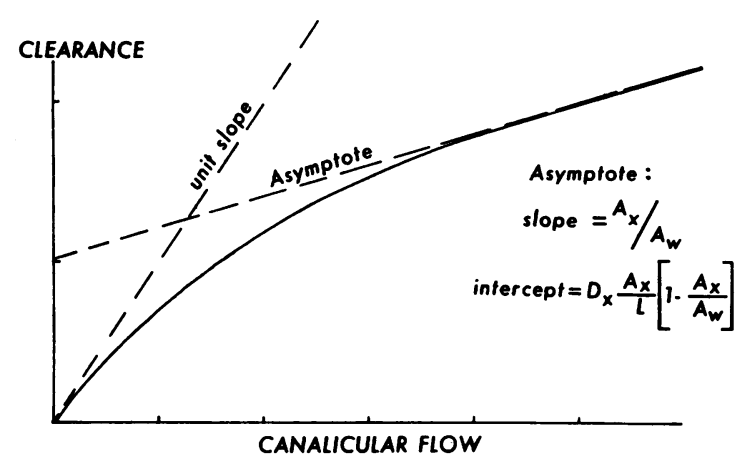

Fig. 6. THE theoretical RElation between SOlUte CLEARANCE AND CANALICULAR BILE FLOW AS DEFINED BY EQuation 5. $A_{x}=$ effective pore area for a permeating solute $x ; \mathrm{A}_{\infty}=$ pore area for water; $\mathrm{D}_{x}=$ unrestricted diffusion coefficient; $L=$ effective pore length.

the asymptote. This limiting slope is the ratio of pore areas accessible to solute and solvent. The intercept of the asymptote at zero flow is equal to $\mathrm{D}_{x}\left(\mathrm{~A}_{x} / \mathrm{L}\right) \sigma$, where $\sigma$ is the Staverman reflection factor, $1-\mathrm{A}_{x} / \mathrm{A}_{\mathrm{w}}(11,12)$.

It is not permissible to use Equation 5 directly since we must allow for the possibility that canalicular flow differs from total flow. Of the various distal mechanisms that might be operative during dehydrocholate choleresis, however, only three are compatible with the experimental results. There may be no net fluid movement across the duct epithelium, or if fluid secretion or reabsorption occurs, these processes appear to operate at rates that are approximately proportional to the flow of canalicular bile.

This conclusion may be more easily appreciated by considering the behavior of Equation 5 after both sides have been divided by $f$.

$$
[x]_{\mathrm{b}}{ }^{\prime} /[x]_{\mathrm{p}}=\frac{\mathrm{f}+\mathrm{D}_{x}\left(\mathrm{~A}_{\mathrm{w}} / \mathrm{L}\right)}{\left(\mathrm{A}_{\mathrm{w}} / \mathrm{A}_{x}\right) \mathrm{f}+\mathrm{D}_{x}\left(\mathrm{~A}_{\mathrm{w}} / \mathrm{L}\right)} .
$$

The form of this equation is presented in Figure 7. The canalicular bile: plasma concentration ratio of a test solute equals 1 when $\mathrm{f}=0$ and declines to a constant value, $A_{x} / A_{w}$, when the diffusion term, $\mathrm{D}_{x}\left(\mathrm{~A}_{\mathrm{w}} / \mathrm{L}\right)$, becomes trivial compared to the terms involving bile flow. Accordingly, Equation 6 has a limiting slope of 0 . In Figure 8 the dehydrocholate data for mannitol and erythritol are shown to conform to this limiting case. Since Equation 6 must have a different curvature for each solute except when its slope is 0 for both 


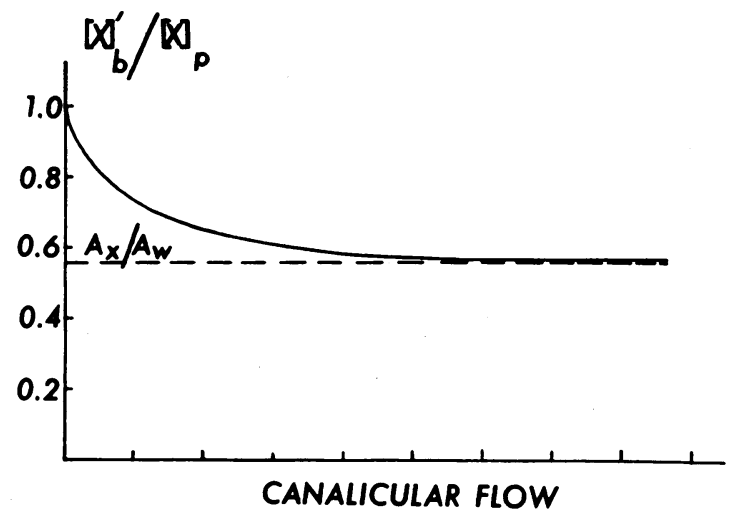

Fig. 7. The theoretical Relation Between the CANALICULAR BILE: PLASMA CONCENTRATION RATIO AND THE RATE OF CANALICULAR BILE FLOW AS DEFINED BY Equation 6.

solutes, it follows that no single transformation could lead to apparent slopes of 0 unless Equation 6 were in each case already close to its asymptote. Solute transfer during dehydrocholate chloresis thus appears to be predominantly the result of solvent flow rather than diffusion. Within the limits imposed by the variability of the observed concentration ratios, it is clear that if Equation 6 applies, the only distal mechanisms that could operate during dehydrocholate choleresis are those that add or subtract a constant fraction of the fluid that arrives in the interlobular ducts.

As a corollary to this conclusion, it is evident that inhibition of net distal fluid reabsorption could not contribute significantly to the choleretic effect

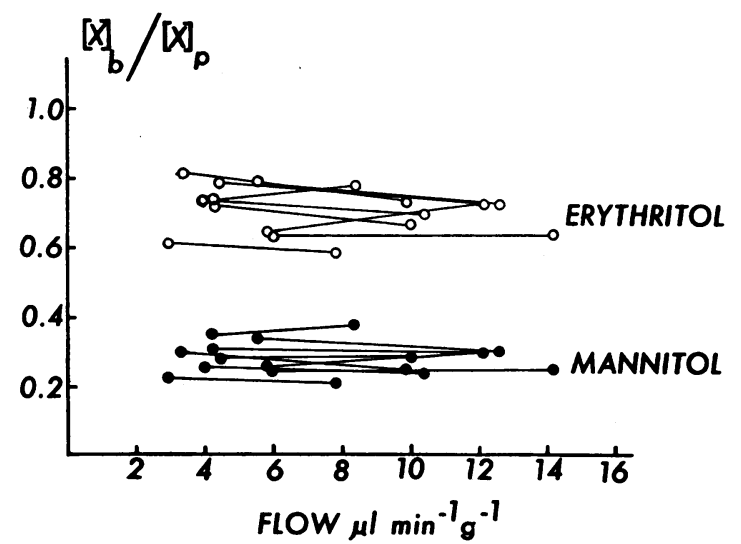

Fig. 8. Bile : Plasma CONCENTRATION RATIOS DURING DEH YDROCHOLATE CHOLERESIS. Average slopes ( $\pm 95 \%$ confidence interval) : erythritol, -0.004 ( \pm 0.006$)$; mannitol, -0.001 ( \pm 0.004$)$. of dehydrocholate. One possibility is that ductular reabsorption of inorganic ions is limited by a maximum electrochemical gradient between plasma and bile. If the limiting gradient is principally determined by the concentration of nonreabsorbable bile salts and if, as suggested by Sperber (4), the rate of canalicular bile formation is determined by the rate of active bile salt secretion, then the combination of proximal fluid secretion and distal fluid reabsorption both determined by bile salt concentration would lead to reabsorption of a constant fraction of canalicular flow. The alternative possibility of net distal fluid secretion must also be entertained. In this case the present data set an upper limit on the possible contribution to total flow. Since the test solutes are assumed to move only by diffusion and filtration, their clearance could not exceed canalicular flow, and accordingly the magnitude of net distal secretion at any value of total flow could not exceed the horizontal distance between the observed clearance line for erythritol and the line with unit slope. From Figure 1 it is estimated that distal secretion could at most contribute one-third of total flow.

The relation of solute clearance to spontaneous flow (Figure 3) conforms in general to the pattern observed in dehydrocholate choleresis. Because each spontaneous flow has been observed in a different animal and the range of flows encountered was small, detailed analysis of the apparent differences is not warranted. Nevertheless, it is clear that different levels of endogenous secretin were not responsible for individual differences in spontaneous flow.

The fact that steady state bile: plasma concentration ratios for mannitol and erythritol do not vary with flow during dehydrocholate choleresis has been interpreted to mean that diffusion plays a negligible role in their transport through the canalicular membrane. It remains to be seen whether a similar postulate will apply to other species in which the flow of bile is substantially less; however, the low values obtained by extrapolating the lines in Figure 1 to $f=0$ suggest that solvent drag would predominate over diffusion at lower flows as well. An explanation for this phenomenon may be formulated in terms of the relative dimensions of equivalent pores. From Equations 2 and 3 it may be seen that diffusion depends on the ratio of pore area to length, whereas solute 
transfer by filtration depends on area alone. It is thus possible to visualize a porous barrier between blood and bile, which though relatively permeable to bulk flow of water and dissolved solutes, nevertheless presents an effective barrier to diffusion. The required pores will be ones in which the crosssectional area, though large enough to accommodate the solutes in question, is yet small in relation to pore length. In considering this explanation, it is important to recall that the use of Equation 2 to interpret the experimental results depends on the assumption of a uniform concentration gradient along the length of the pore. This source of error, though unavoidable, may be important if the diffusion path is long or if rapid solvent flow distorts the static concentration profile within the membrane.

\section{Acknowledgments}

It is a pleasure to acknowledge the expert technical assistance of Mr. Halvor Sornson and the valuable advice of Drs. Adrian Hogben and Robert Barker.

\section{References}

1. Cook, D. L., C. A. Lawler, L. D. Calvin, and D. M. Green. Mechanisms of bile formation. Amer. J. Physiol. 1952, 171, 62.
2. Schanker, L. S., and C. A. Hogben. Biliary excretion of inulin, sucrose, and mannitol: analysis of bile formation. Amer. J. Physiol. 1961, 200, 1087.

3. Chenderovitch, J., E. Phocas, and M. Rautureau. Effects of hypertonic solutions on bile formation. Amer. J. Physiol. 1963, 205, 863.

4. Sperber, I. Secretion of organic anions in the formation of urine and bile. Pharmacol. Rev. 1959, 11, 109.

5. Wheeler, H. O., and P. L. Mancusi-Ungaro. Role of bile ducts during secretin choleresis in dogs. Amer. J. Physiol. 1966, 210, 1153.

6. Forker, E. L., and C. A. M. Hogben. Diodrast transit time in guinea pig biliary tree. Amer. J. Physiol. 1967, 212, 104.

7. Bray, G. A. A simple efficient liquid scintillator for counting aqueous solutions in a liquid scintillation counter. Analyt. Biochem. 1960, 1, 279.

8. Natrella, M. G. Experimental Statistics. Washington, D. C., U. S. Government Printing Office, 1963.

9. McCorkindale, J., and N. L. Edson. Polyol dehydrogenases. 1. The specificity of rat-liver polyol dehydrogenase. Biochem. J. 1954, 57, 518.

10. Renkin, E. M. Filtration, diffusion, and molecular sieving through porous cellulose membranes. J. gen. Physiol. 1954, 38, 225.

11. Staverman, A. J. The theory of measurement of osmotic pressure. Rec. Trav. chim. Pays-Bas 1951, 70, 344.

12. Durbin, R. P. Osmotic flow of water across permeable cellulose membranes. J. gen. Physiol. 1960, 44, 315. 